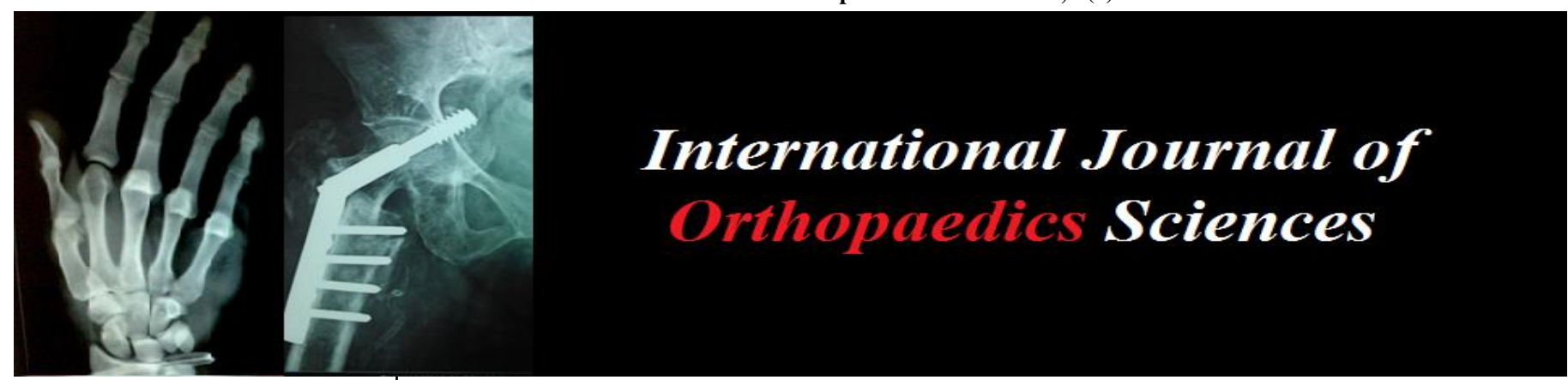

E-ISSN: 2395-1958

P-ISSN: 2706-6630

IJOS 2020; 6(3): 841-844

(C) 2020 IJOS

www.orthopaper.com

Received: 07-05-2020

Accepted: 09-06-2020

Sandeep MMR

Associate Professor,

Department of Orthopaedics,

PSG Hospitals, PSGIMSR,

Peelamedu, Coimbatore,

Tamil Nadu, India

Dinakar Rai

Professor, Department of

Orthopaedics, PSG Hospitals,

PSGIMSR, Peelamedu,

Coimbatore, Tamil Nadu, India

Corresponding Author:

Dinakar Rai

Professor, Department of

Orthopaedics, PSG Hospitals,

PSGIMSR, Peelamedu,

Coimbatore, Tamil Nadu, India

\section{A modified dynamic hip screw in unstable intertrochanteric fracture: A retro-prospective study}

\author{
Sandeep MMR and Dinakar Rai
}

DOI: https://doi.org/10.22271/ortho.2020.v6.i3m.2291

\section{Abstract}

Background: Intertrochanteric fractures occur mostly in elderly patients, and the outcome may be extremely poor if there is prolonged bed-rest.

Many treatment modalities have come up in management of these unstable intertrochanteric fractures. Sliding Hip Screw Fixation is still the gold standard in treatment of stable intertrochanteric fracture. In unstable comminuted intertrochanteric fractures, there is high incidence of failure in view of excessive collapse seen with Dynamic hip screw.

In order to limit the collapse we have done a modification on Dynamic Hip Screw implant. The aim of this study is to assess fracture healing, collapse and implant failure, in unstable intertrochanteric fractures (Boyd and Griffin type-2) treated by modified DHS fixation.

Methods: 23 patients who were operated with modified DHS for unstable intertrochanteric fracture were selected using random selection and following parameters were noted from the records.

Results: Out of 23 patients in this study, 20 patient showed fracture healing (87\%) with or without minimal collapse and 3 patient had non-union (13\%) at the end of 5 months follow up. Ultimately all fractures united at the end of 1 year followup.

Conclusion: Modified Dynamic Hip Screw has showed improved results as compared to normal Dynamic Hip Screw in treating communited intertrochanteric fracture, which limits the collapse at fracture site.

Keywords: Intertrochanteric fractures, modified DHS, collapse

\section{Introduction}

Intertrochanteric fractures occur mostly in elderly patients, and the outcome may be extremely poor if there is prolonged bed-rest. The best treatment for trochanteric fracture remains controversial ${ }^{[1-3]}$. Many methods have been recommended ${ }^{[4-6]}$. Early mobilization of these patients reduces the morbidity and mortality rate.

Intertrochanteric fractures with severe communition and displacement are commonly seen in elderly patients. Most of the elderly patients have poor bone quality due to which fractures are often associated with complications like non-union, implant failure and femoral head perforation.

Management of unstable intertrochanteric fractures is challenging because of excessive collapse, loss of fixation, implant failure, lag screw cut out and in addition osteoporosis also adds to the complication resulting in unpredictable outcome.

In order to limit the collapse we have done a modification on Dynamic Hip Screw implant. In this study we are assessing the outcome of unstable intertrochanteric fractures treated with modified dynamic hip screw fixation designed by us.

Boyd and Griffin (1949) classified fractures in the trochanteric area of femur into 4 types. Their classification included all fractures from extra capsular part of neck to a point $5 \mathrm{~cm}$ below the lesser trochanter. Their classification is useful in planning treatment and estimating prognosis ${ }^{[7]}$.

Type 1: Fractures that extend along the intertrochanteric line from the greater to the lesser trochanter. Reduction usually is simple and is maintained with little difficulty. Results generally are satisfactory. 
Type 2: Comminuted fractures, the main fracture being along the line, but with multiple fractures in the cortex. Reduction of these fractures is more difficult because the comminution can vary from slight to extreme. A particularly deceptive form is the fracture in which an anteroposterior linear fracture occurs, as in type 1, but with an additional fracture in the coronal plane, which can be seen on the lateral radiograph.

Type 3: Fractures that are basically subtrochanteric with at least one fracture passing across the proximal end of the shaft just distal to or at the lesser trochanter. Varying degrees of comminution are associated. These fractures usually are more difficult to reduce and result in more complications during surgery and convalescence period.

Type 4: Fractures of the trochanteric region and the proximal shaft, with fracture in at least two planes, one of which usually is the sagittal plane and may be difficult to see on routine anteroposterior radiographs. If open reduction and internal fixation are used, twoplane fixation is required because of the spiral, oblique, or butterfly fracture of the shaft.

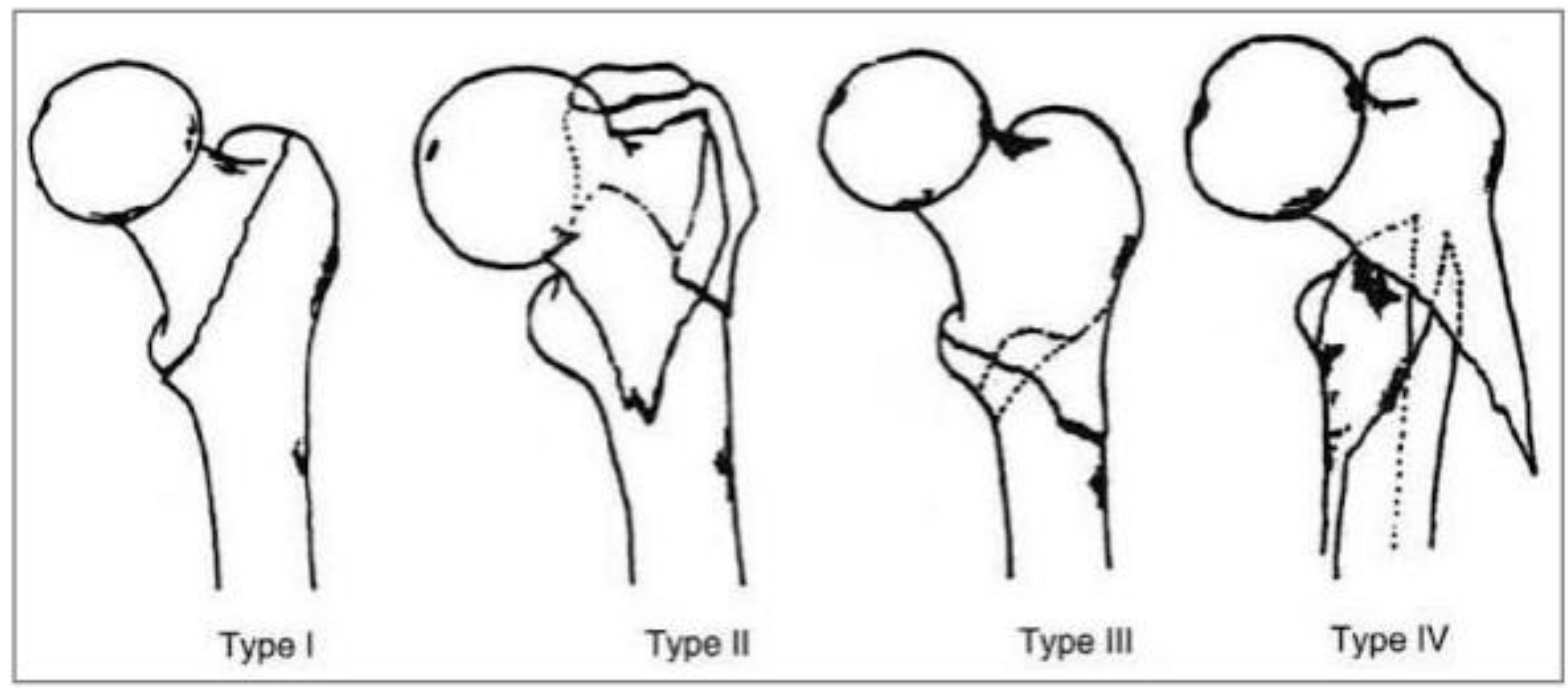

\section{Aim of the study}

The aim of this study is to assess fracture healing, collapse and implant failure, in unstable intertrochanteric fractures (Boyd and Griffin type-2) treated by modified DHS fixation.

\section{Objectives}

1. To assess fracture healing, collapse in management of communited intertrochanteric fracture with modified Dynamic Hip Screw.

2. To look for implant failure- migration of implant, implant loosening, implant cutout or non-union.

\section{Materials and Methods}

Study Design: Retrospective observational study population: Patients diagnosed to have intertrochanteric fractures and treated with Modified DHS Study Area : PSG Hospitals.

\section{Inclusion criteria}

1. Boyd and griffin classification type-2 fractures only

2. Patients willing for treatment and given written informed consent.

\section{Exclusion criteria}

1. Boyd and griffin classification type-1, type-3 and type -4

2. Pathological fractures

3. Infection

4. Treated after 3 weeks of trauma.

5. Patients medically unfit for surgery.

6. Compound fractures associated with vascular injuries, ipsilateral femoral shaft fractures and pelvic fractures.

7. Patients not willing for treatment.

23 patients who were operated with modified DHS for unstable intertrochanteric fracture were selected using random selection and following parameters were noted from the records.

The criteria taken into consideration were fracture healing, collapse of fracture fragments, implant failure

\section{About Modified Dynamic Hip Screw}

One of the cause for failure of Dynamic Hip Screw is over collapse at fracture site ${ }^{[8]}$.

In this study, we have used modified dynamic hip screw to limit the over collapse which is undesired in unstable intertrochanteric fractures. In this implant we have done modification in the shaft of lag screw, we have reduced the length of keyed screw system, so that we can have a maximum of $1 \mathrm{~cm}$ collapse, hence there will be limitation in collapse unlike the original implant.

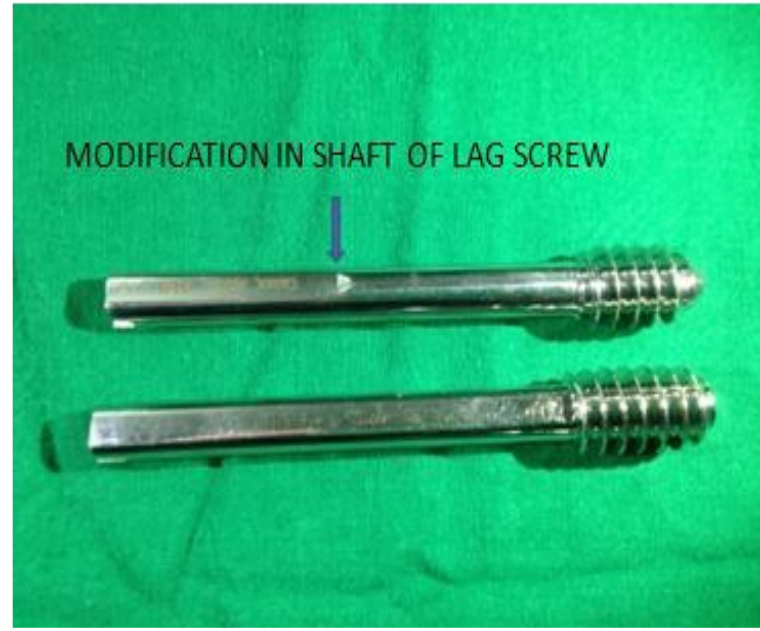

Modified lag screw versus Normal lag screw 


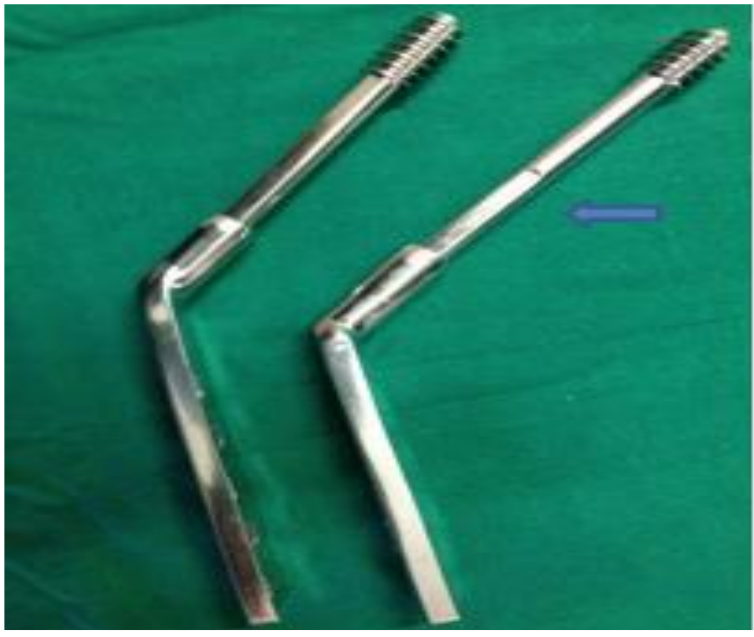

Before collapse

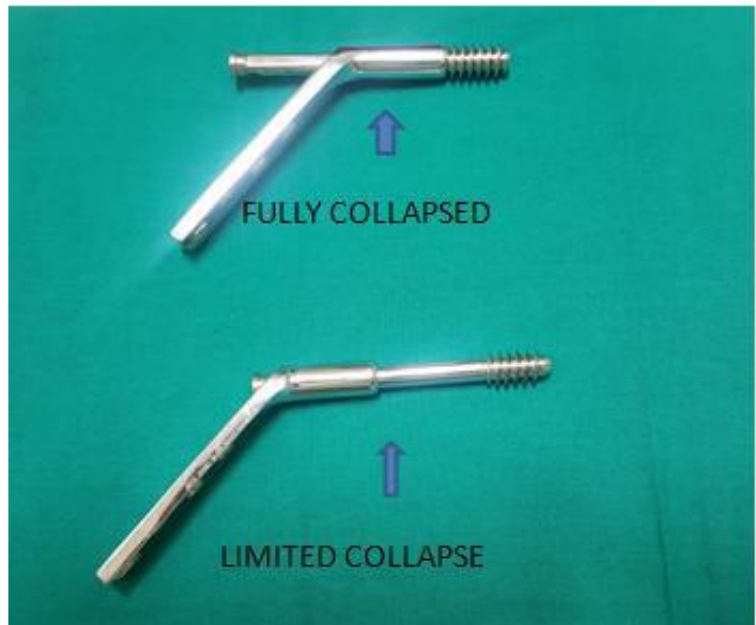

After collapse

\section{Results}

In this retro-prospective study a total of 23 patients were assessed. Pre-operative

AP radiographs of pelvis was taken for all the patients who were treated by modified dynamic hip screw fixation. All patients who underwent treatment were of age from 38 years to 90 years. Out of 23 patients in this study, 13 patients were male $(56.5 \%)$ and 10 patients were female (43.5\%). Only boyd and griffin type-2 fractures were taken in view of

standardisation. Post-operatively follow up xray were taken at 1st month, 3rd month and 5th month and the outcome was assessed.

Factors assessed were

1. Fracture healing

2. Fracture collapse

3. Implant failure

\section{Fracture Healing}

1st month 3rd month 5th month

\begin{tabular}{|c|c|c|c|}
\hline & $\mathbf{1}^{\text {st }}$ month & $\mathbf{3}^{\text {rd }}$ month & $\mathbf{5}^{\text {th }}$ month \\
\hline Union & $8(34.8 \%)$ & $20(87 \%)$ & $20(87 \%)$ \\
\hline Non union & $15(65.2 \%)$ & $3(13 \%)$ & $3(13 \%)$ \\
\hline Total & $23(100 \%)$ & $23(100 \%)$ & $23(100 \%)$ \\
\hline
\end{tabular}

Out of 23 patients in this study, at first month follow-up, 8 patients showed fracture healing (34.8\%), at third month follow-up, 20 patients showed fracture healing (87\%), at fifth month follow-up, 20 patient showed fracture healing (87\%) and three patient had non-union (13\%)

Fracture Collapse

\begin{tabular}{|c|c|}
\hline & $\mathbf{1}^{\text {st }}$ month \\
\hline Minimal collapse & $16(69.6 \%)$ \\
\hline No collapse & $7(30.4 \%)$ \\
\hline Total & $23(100 \%)$ \\
\hline
\end{tabular}

Out 23 patients in this study, at first month follow-up, 7 patients showed no Collapse (30.4\%) and 16 patients showed minimal collapse $(69.6 \%)$ [less than $1 \mathrm{~cm}$ ], however the collapse rate remained same for all patients till end of this study.

Implant Failure

\begin{tabular}{|c|c|c|c|}
\hline & $\mathbf{1}^{\text {st }}$ month & $\mathbf{3}^{\text {rd }}$ month & $\mathbf{5}^{\text {th }}$ month \\
\hline No implant failure & $19(82.6 \%)$ & $19(82.6 \%)$ & $19(82.6 \%)$ \\
\hline $\begin{array}{c}\text { Lag screw migration not } \\
\text { breaching cortex }\end{array}$ & $4(17.4 \%)$ & $4(17.4 \%)$ & $4(17.4 \%)$ \\
\hline
\end{tabular}

At the end of 5 months followup out of 23 patients, 4 patient had implant migration not breaching cortex $(17.3 \%)$.

\section{Radiographs}

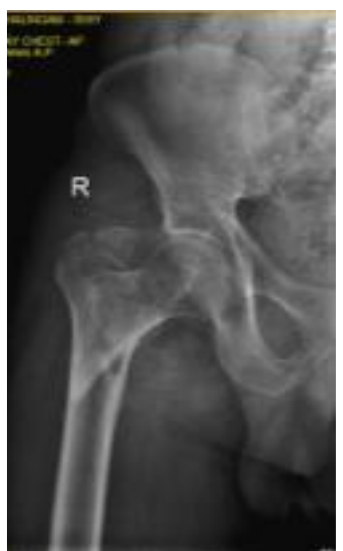

Pre op

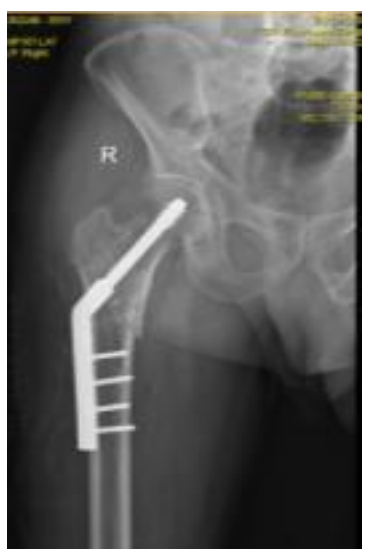

Post op

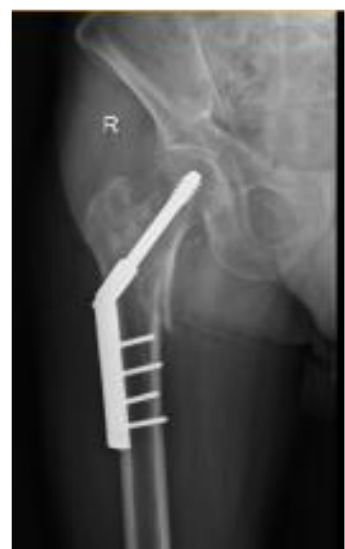

$1^{\text {st }}$ month

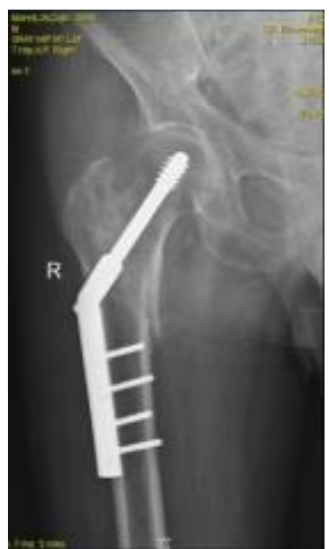

$3^{\text {rd }}$ month

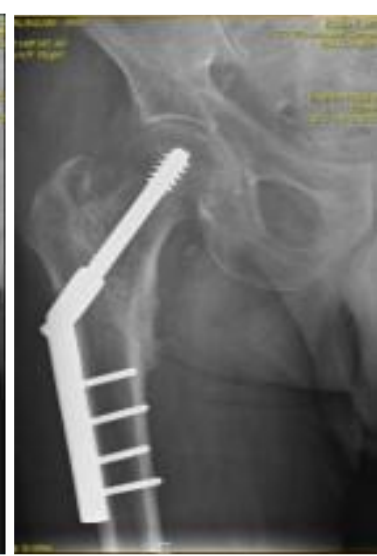

$5^{\text {th }}$ month

\section{Discussion}

Intertrochanteric fractures are mainly treated by surgical intervention. Despite longterm experience in many centres, there have been factors still contributing to pooroutcome of managing unstable intertrochanteric fractures.

Controversies persist because there is lack of proper per- 
operative risk factors assessment that affect the outcome in these fractures treated by various methods. Failures of Dynamic hip screw in unstable intertrochanteric fracures are due toover collapse at fracture site ${ }^{[8]}$.

In this study, we have used modified Dynamic Hip screw for treating comminuted intertrochanteric fractures, we have used this implant to limit the over collapse at fracture site.

Fracture united in 20 patients with minimal collapse and 3 patients had no signs of union at the end of 5 months. But all fractures united at the followup period of 1 year, lag screw migration occurred in 4 patients who started early weight bearing.

Nordin $S$ in their study on treatment of intertrochanteric fractures with Dynamic Hip Screw, 83.3 percent of patients had fracture healing at one month ${ }^{[9]}$. In our seriesonly 34.8 percent of patients showed fracture healing at first month, however at the endof fifth month $87 \%$ fractures went on to heal. This delay in fracture healing relates to the modification in design of implant which limits the collapse at fracture site.

Sadowski cal et al. in their study on treatment of unstable intertrochanteric fractures with sliding hip screw, implant failure and non-union was noted in 7 of 19patients (38\%) who had been treated with the sliding hip screw ${ }^{[10]}$. In our series, implant migration was noted in 3 out of 23 patients (13\%) but no breaching of cortex occured. This results compare favourably and highlights the advantage of modified Dynamic Hip Screw in treatment of communited intertrochanteric fractures.

\section{Conclusion}

Modified Dynamic Hip Screw has showed improved results as compared to normal Dynamic Hip Screw in treating communited intertrochanteric fracture.

1. Fracture healing was slow in comparing with regular Dynamic hip screw.

2. Modified Dynamic hip screw significantly limits the collapse at fracture site.

3. When modified Dynamic Hip Screw is used in managed of communited intertrochanteric fracture, weight bearing mobilisation should be delayed to improve the outcome.

\section{Limitations}

\section{Small sample size}

Other forms of fixation of trochanteric fractures were not compared in this study.

\section{References}

1. Babhulkar S. Management of trochanteric fractures. Indian Journal of Orthopaedics. 2006; 40(4):210

2. Rockwood C, Green D, Bucholz R. Rockwood and Green' fractures in adults, Philadelphia: Lippincott Williams \& Wilkins, 2006.

3. Singh A, Thong G, Laloo N, Singh A, Singh S. Management of trochanteric fractures. Indian Journal of Orthopaedics. 2006; 40(2):100.

4. Cooper A. Fractures and Dislocations of Joints.10th ed. London, 1839

5. Bick E. Source Book of Orthopaedics. Newyork: hafner, 1968.

6. Heyse-moore et al. treatment of intertrochanteric fractures of femur JBJS. 1983; 65-B:262-267

7. Whitmann R. A new method of treatment for fractures of the neck of the femur, together with remarks on coxavara. Ann Surg. 1902; 36:746.

8. Mohan N, Chandrashekar H. An Analysis of Failure of
Dynamic Hip Screw with Plate in the Management of Intertrochanteric (IOSR-JDMS) e-ISSN: 2279-0853, pISSN: 2279-0861. 2014; 13(3, IV):54-57

9. Nordin S, Mechanical fixation of DHS in intertrochanteric fracture Med J Malaysia. 2001; 56(D):12-7.

10. Sadowski CAL. Treatment of reverse oblique and transverse interrochanteric fractures with use of an intramedullary nail or a $95 \mathrm{deg}$ screw. JBJS Am. 2002; $84 ; 372-381$

11. Capener N. The treatment of pertrochanteric fractures. JBJS Br. 1957; 39-b(3):436-437.

12. Taylor MN, Janzen J. Internal fixation for intertrochanteric fractures JBJS Am. 1944; 26(4):707712.

13. Boyd HGLL. Classification and treatment of trochanteric fractures. Ach Surg. 1949; 58:853-863.

14. Boyd H, Anderson LD. Management of unstable trochanteric fractures. Surggynecol Obstrtrics 1961; 55:853-863.

15. Bendo JA, Weiner LS, Strauss E et al. Collapse of interochanteric hip fractures fixed with sliding screws. orthop Rev, 1944, 30-37.

16. Dimon JHJC. Unstable intertrochanteric fravtures. JBJSAm. 1967; 49(3):440-450.

17. Harrington KJ. The management of communited unstable intertrochanteric fracture. JBJS Am. 1973; 55(7):13671376

18. Sarmiento A. Intertrochanteric fractures of femur. JBJS. 1995; 75(3):90-92

19. Desjardins Ara, Paiement G Newman N, et al. Unstable intertrochanteric fracture of femur. JBJS Br. 1993; 75(3):445-447.

20. Gargan MGR, Simpson Ah. How effective are osteotomies for unstable intertrochanteric fractures 